\title{
Reliability and validity of an observational system to qualify performance indicators in goalball matches: Scal-Go proposal
}

Isabella Alves ${ }^{1}$, Leonardo Gomide ${ }^{1}$, Maria Julia Rocha ${ }^{1}$, Tatiana Vizu ${ }^{1}$, Rodrigo Aquino ${ }^{2}$, Rafael Menezes $^{1}$, Otávio Furtado ${ }^{3}$ and Márcio Morato ${ }^{1}$

Received: $11^{\text {th }}$ December 2020; Accepted: 25 $5^{\text {th }}$ May 2021; Published: $1^{\text {st }}$ February 2022

\begin{abstract}
Which situations compose the success and failure in goalball matches? Our aims were to develop a scale to assess performance indicators in goalball and, to evaluate this proposed scale according to contextual variables (i.e., team level, match outcome and match status). Non-participant match observation method was applied in 24 goalball matches from the Paralympic Games 2016. Firstly, an observational system development was composed by performance indicators (named as Scal-Go). Success and failure from offensive and defensive phases were stratified into a spreadsheet. Following, inter and intra reliability stages were conducted together with content validity, certified by goalball's experts. Scal-Go achieved high agreement levels for inter- (.752 and .919) and intra-observers (.846 and .974) reliability. Also, content validity was certified by goalball experts. The results showed high frequency of standard preceding actions (80.3\%), strongly appropriate defences (57.8\%), and acceptable attacks (57.4\%). In addition, since players' performance was associated to contextual variables, specific actions and situations are performed differently within team levels, match outcome, and match status. Match interruptions, accurate shots, goal scored first, quick defences, defensive infraction and penalty situations must be included in training process.
\end{abstract}

Keywords: adapted physical activity; performance analysis; qualification system; para sport

\section{Introduction}

Scoring goals is the ultimate determinant of a successful goalball team. This arises from ten-goals lead, or by scoring the highest number of the adversary's goals after two halves of 12 minutes each (International Blind Sports Federation, 2020). Successful attacks means that offensive principles (ball control, attack preparation, and throw) were properly performed and resulted in a goal, or at least disturbed the opponent's defence (Morato et al., 2012). In this sense, defensive principles (defensive balance, throw reading, and blocking) (Morato et al., 2012) can be affected and contribute to an improper performance. Likewise, the team can self-organize and to perform a proper defence. This complexity of elements exposed in phases (i.e., attack, defence and transition between them) into a cyclic organized match system suggests for coaches how to understand and proceed to apply training for goalball players (Morato et al., 2012). However, the understanding along the match about the variance from appropriate to inappropriate actions must be deep investigated. In addition to just describe the actions performed during matches, the tactical-technical profile qualification must consider valid procedures for team's sports assessments (Costa et al., 
2011). This point of view has been investigated in some Paralympic Team Sports (Francis et al., 2019a, 2019b, 2021; Gómez et al., 2014; Marszałek et al., 2018; Molik et al., 2017), however remains little-known in the literature about goalball.

Performance indicators are widely used to assess individual and team's actions during a match (Hughes \& Bartlett, 2002). Key-variables into an observational system based on empirical observation composes a notational analysis (O'Donoghue, 2010), generally applied on behalf of coaches and performance analytics requirements. Match analysis performance was developed and replicated in different wheelchair basketball competitions (Francis et al., 2019b, 2019a; 2021) and within gender (Gómez et al., 2014). A specific observational system for post-event analysis was created and filled the validity criteria (Francis et al., 2019a). From this, key dynamic variables were associated with team success (Francis et al., 2019b) and wheelchair basketball players' performance was influenced by specific contextual variables (e.g., match status and sport class, Francis et al., 2019b; ranking order at the competition, Francis et al., 2021, and; match outcome, Gómez et al., 2014). On regard of Paralympic non-invasion teams' sports, a Game Performance Sheet for Sitting Volleyball was developed, validated, and applied to compare the effectiveness in offensive and defensive match's parameters within types of disability and the vertical reach in seated position (Molik et al., 2017) and also to analyse a contextual variable in relation to match performance (Marszałek et al., 2018). A strong relationship between vertical reach and its effectiveness in sitting volleyball was presented. Furthermore, comparisons between match performance and quality of opposition showed the main factors presented in the best teams of final competition's ranking: attack effectiveness, block, number of all attempts of attack and serve increases the probability of winning the set (Marszałek et al., 2018).

Insights on structural perspectives of notational analysis in goalball were previously demonstrated in literature. On the basis of exhaustive analysis (classification of the entirely match) and exclusivity (each variable refers only one action) criteria (Anguera \& Mendo, 2013), all possible actions performed during goalball matches were previously categorized into a reliable protocol (Morato et al., 2017). These authors classified and described offensive and defensive principles and divided in observational categories, performance indicators and its description. Some of these actions already demonstrated increased probabilities of scoring a goal. For example, faster balls (Bowerman et al., 2011; Monezi et al., 2019; Morato et al., 2018), straight shots, using spin and bounce throw technique, with properly targets (i.e., between defenders) are related to goal scoring (Link \& Weber, 2018). Attack by throwers with visual impairments (i.e., low vision) and defence by athletes with blindness have high probability to score and defend a goal respectively, since visual usability may influence in attack and defence efficacy (Molik et al., 2015). All these above-mentioned possibilities of actions could be varied for a team or an individual during the competition or in training sessions.

However, within a dynamic system (McGarry et al., 2002; Silva et al., 2013), goalball arises from offensive and defensive cycles and their interactions with the opponent and environment (Morato et al., 2012). In this sense, contextual factors (e.g., team level, match outcome, match status) could influence team's and player's performance (Taylor et al., 2008; 2010) as previously mentioned for Paralympic Sports (Francis et al., 2019b; 2021; Gómez et al., 2014; Marszałek et al., 2018). Team level and match status (i.e., the team or a player is winning, drawing or in a losing situation at the moment of the behaviour noted) has been required as a useful tool to categorize successful and unsuccessful teams during a competition (Castellano et al., 2012; Taylor et al., 2008; Taylor et al., 2010). These contextual variables (i.e., team level, match outcome, match status) presented significant influence in team's sports performance (Almeida et al., 2014; Taylor et al., 2008). It should 
be required to guide the training (Taylor et al., 2010) and strategy to the competition. To date, no study has yet described and compared match outcome, team level and match status in goalball matches. Nevertheless, even though there is a reliable and comprehensive observational system for goalball match analysis in the literature, it does not include the qualification of performance indicators associated with contextual variables (Morato et al., 2017). Thus, in line to contribute for tactical-technical profile qualification in goalball, the aim of the present study was twofold: (i) to develop a scale to assess performance indicators in goalball and, (ii) to evaluate this proposed scale according to contextual variables (i.e., team level, match outcome and match status).

introduction should briefly place the study in a broad context and highlight why it is important. It should define the purpose of the work and its significance. The current state of the research field should be reviewed carefully and key publications cited. Please highlight controversial and diverging hypotheses when necessary. Finally, briefly mention the main aim of the work and highlight the principal conclusions. As far as possible, please keep the introduction comprehensible to scientists outside your particular field of research. As a general rule, no more than 40 references should be cited in a full text original article (120 in review article). References are listed in accordance with PMAPA $7^{\text {th }}$ Edition. See the end of the document for further details on how to put the references in the reference list using PMAPA $7^{\text {th }}$ Edition.

\section{Materials and Methods}

\section{Match sample}

A non-participant systematic match observation method was used as scientific approach for data analysis (Anguera \& Mendo, 2013; Thomas et al., 2012). The match sample was composed by 24 video recordings of male goalball teams from the Paralympic Games 2016. All videos were acquired from national team coaches, who had a space reserved to record the matches during the competition. This space was located in a longitudinal position in relation to the goalball court with approximately 20 meters from the ground. Four matches were excluded of the analysis because they did not meet the inclusion criteria: full video recording available $(n=1)$, numerical equality of 3 vs. 3 players $(n=1)$, and the official match's length without wins from ten-goal lead by a team $(n=2)$. The videos were shared by performance analysts and researchers who were granted permission to video recording the matches from the International Blind Sports Federation (IBSA). The present study was approved by the Human Research Ethics Committee of the University of São Paulo (School of Physical Education and Sport, Ribeirão Preto, Brazil; protocol number: 93692318.0.0000.5659) and it was conducted in accordance with the Helsinki declaration. Permission for using the recorded videos for scientific purposes was granted by the International Paralympic Committee Sports Science Working Group.

\section{Procedures}

Three stages (system development, reliability, and validity) composed the design and application of a specific performance observational goalball's system, called Scal-Go. First step was based on independent and dependent output development to characterize the constituent elements of success and failure in each phase during the goalball match [i.e., preceding situation (relation between offensive and defensive transitions), attack, and defence]. Following, three independent observers established and agreed on the match analysis criteria and contributed for the inter and intra reliability stage. Validity was achieved using two postulates: reliability and content validity (Cronbach, 1988; O’Donoghue, 2010). 


\section{System development}

The Scal-Go was proposed to qualify all attacks, defences and their preceding situation over goalball matches. A specific observational system was designed in spreadsheet ad hoc sequence using the Microsoft $\AA$ Excel, which included the following variables (Figure 1): match label, offensive team (OT), thrower (T), defensive team (DT), defender (D), match outcome (MO), team level (TL), score, match status for attacking team (MS_A), match status for defending team (MS_D), relative quality for preceding situation (RQ_PS), relative quality for attack (RQ_A), start/stop (begin and end of defence), length (total length of defence), relative quality for defence (RQ_D), and outcome (O). This sequence was designed by ensuring the regular self-organizing cycles of a goalball match (Morato et al., 2012). Match label was designated for team's abbreviation names and the match respective score (e.g., SWE 12 X ALG 6, for a match between Sweden and Algeria). Both offensive and defensive team's descriptions depended of ball possession control. For this, it was also fixed the team's abbreviation names (e.g., offensive team = SWE and, defensive team $=$ ALG). Thrower and defender were noted by the number printed in player's uniform. Thrower was designated by who threw the ball to the opponent and defender by who did the first defensive contact with the ball.

\section{Dependent and independent variables}

The relative quality for preceding situation, attack and defence were considered as the dependent variables. Using a likert scale, a logical filling sequence was created and a number between 1 and 3 was assigned to temporally categorize the preceding situation. The criterion for choices considered the length's characteristics of preceding situation [short (1), standard (2), and extended (3); Table 1]. For attack and defence's qualifications a number between 1 to 5 was placed considering the probability of scoring a goal (Picolo et al., 2021) and the final result of attack and defence's interaction (i.e., goal, block, block out, outside throw, penalty or infraction) [strongly inappropriate (1), inappropriate (2), acceptable (3), appropriate (4), and strongly appropriate (5); Table 2]. The start/stop (beginning and end of defence) and length (total length of defence) were also used to qualify the defence. Specifically, during a block out's result, the end of defence was considered by two forms: (i) with ball "line out" referee signaling, the defence's end was noted by the from "line out" whistle; or (ii) without ball "line out" referee signaling, the defence's end was considered by the first ball contact on the court floor, after the ball being replaced by the referee.

Three independent variables were included (Aquino et al., 2020; Lago, 2009): (i) team level; (ii) match outcome; and (iii) match status. Team level was classified according to the final classification at competition: strong teams (positions first to fourth, $n=2,499$ events counted) or weak teams (positions fifth to tenth, $n=2,028$ events counted). Match outcome was based in the final result of each match [winner teams ( $n=2,219$ events counted) vs. loser teams ( $n=2,308$ events counted)]. Match status was considered when the teams were winning ( $n=1,801$ events counted), drawing ( $n=824$ events counted), or losing $(n=1,902$ events counted).

Table 1. Scale of relative quality (Scal-Go) for preceding situation.

\begin{tabular}{lll}
\hline Short 1 & Standard 2 & Extended 3 \\
\hline Counter-attack (without attack & Balanced self-organized & Official interruption \\
preparation, athletes thrown & cycle (without counter- & (i.e., team official's and medical \\
the ball at the same spot and & attack or match & time out or substitutions) half \\
moment they defended) & interruption) & $\begin{array}{l}\text { time, after goal situation, or } \\
\text { penalty situation }\end{array}$ \\
\hline
\end{tabular}




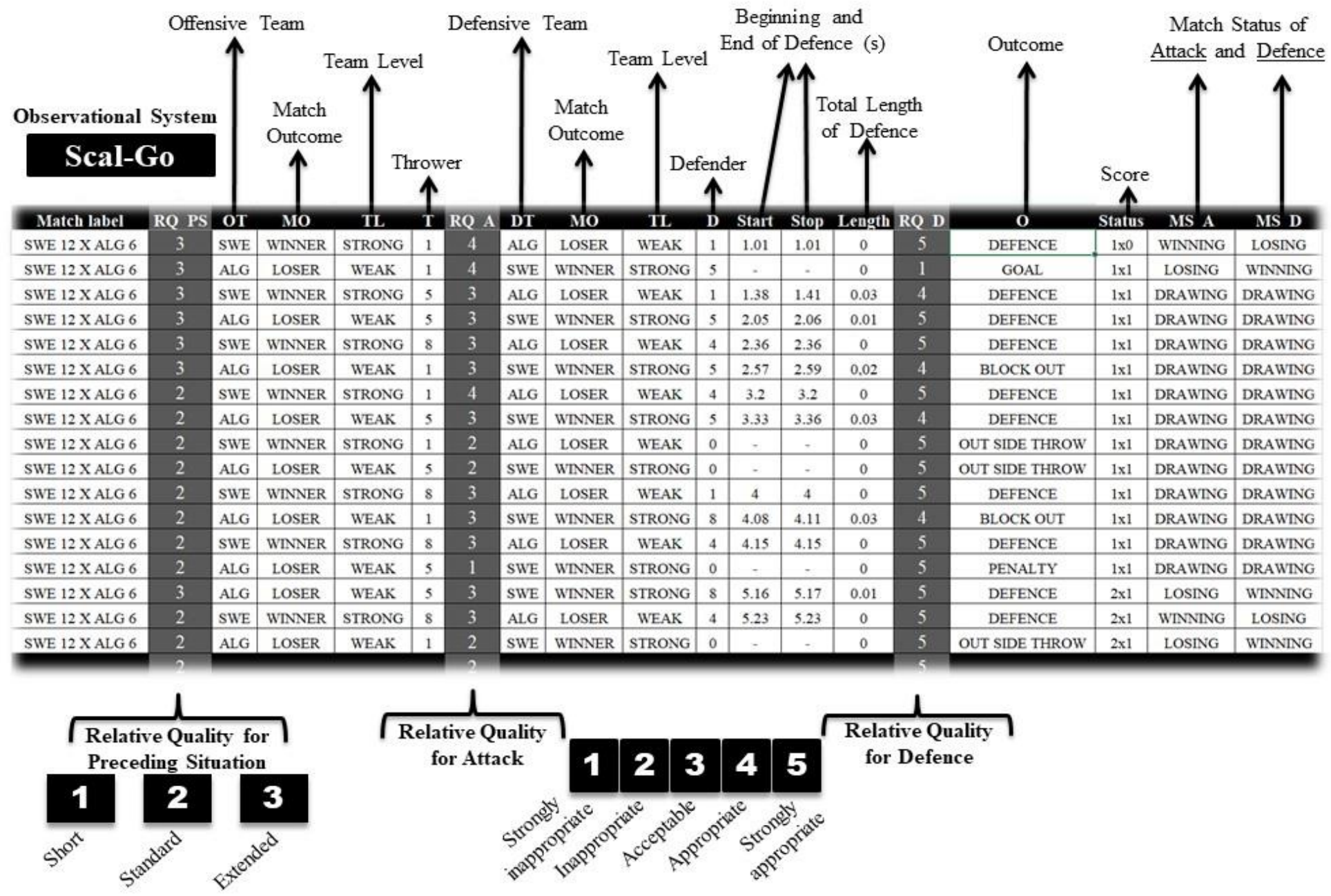

Figure 1. Observational system for goalball match qualification: Scal-Go. 
Table 2. Scale of relative quality (Scal-Go) for attack and defence phases.

\begin{tabular}{|c|c|c|c|c|c|}
\hline & $\begin{array}{l}\text { Strongly } \\
\text { Inappropriate } 1\end{array}$ & Inappropriate 2 & Acceptable 3 & Appropriate 4 & $\begin{array}{l}\text { Strongly Appropriate } \\
5\end{array}$ \\
\hline Attack & $\begin{array}{l}\text { Pentaly or goal } \\
\text { against }\end{array}$ & $\begin{array}{l}\text { Infractions } \\
\text { (i.e., pass out } \\
\text { or premature } \\
\text { throw), outside } \\
\text { throw, or } \\
\text { safety throw }\end{array}$ & $\begin{array}{l}\text { Throw in the } \\
\text { central body } \\
\text { segment of } \\
\text { defender (arms, } \\
\text { head, chest, hip } \\
\text { thigh, or knee) }\end{array}$ & $\begin{array}{l}\text { Throw in the } \\
\text { body extremities } \\
\text { of defender } \\
\text { (forearms, } \\
\text { hands, legs, or } \\
\text { feet) }\end{array}$ & $\begin{array}{l}\text { Goal between two } \\
\text { defenders, or } \\
\text { between a defender } \\
\text { and the goalpost }\end{array}$ \\
\hline Defence & Goal conceded & $\begin{array}{l}\text { Infraction } \\
\text { (i.e., ball over) }\end{array}$ & $\begin{array}{l}\text { Ball time control } \geq \\
4 \text { seconds }\end{array}$ & $\begin{array}{l}\text { Ball time } \\
\text { control between } \\
2 \text { to } 3 \text { seconds }\end{array}$ & $\begin{array}{l}\text { Ball time control } \leq 1 \\
\text { second (without } \\
\text { rebounds), opponent } \\
\text { outside throw, or } \\
\text { opponent penalty }\end{array}$ \\
\hline
\end{tabular}

Note: safety throws were considered situations when players instead of exceeding 10 seconds and to commit a penalty they throw the ball outside deliberately (Morato et al., 2017).

\section{Statistical analysis}

IBM $₫$ SPSS $₫$ for Windows Statistical Packstage (v. 20.0) with statistical significance level set at $5 \%$ was employed for all data analysis. The Kappa index for categorical variables (Fleiss et al., 2013) was used for the reliability analysis (Hopkins, 2000; O’Donoghue, 2010). Three random selected matches (12.5\% of sample size) were used to determine the interobserver reliability from three observers (I. S. A., L. G., and M. J. R.). One match (4,2\% of sample size) composed the intra-observer reliability, applied by one researcher (I. S. A.), with 15-day time-interval between both observations (O'Donoghue, 2010). The establishment of validity was conducted using reliability and content validity postulates (Cronbach, 1988; O’Donoghue, 2010). Content validity was achieved by goalball specialists (Anguera \& Mendo, 2013; O'Donoghue, 2010). They ensured the ecological validity (Davids, 1988) with all relevant performance indicators placed into our observational system.

Data analyses were conducted using: (i) the event as unit of analysis (i.e., composed by preceding situation, attack and defence, represented by each line into spreadsheet ad hoc sequence - Figure 1). In this stage, the chi-square test was applied to describe the frequency of relative quality between strongly appropriate to strongly inappropriate actions performance; (ii) the match as unit of analysis where mean percentage for parametric data and median percentage for non-parametric data of events per match. Here, the t-test (independent samples) was performed for team level (strong vs. weak teams) and the t-test (paired samples) was executed for match outcome (winner vs. loser teams). The Wilcoxon's rank signed test was incorporated when the Shapiro-Wilk test revealed several cases of nonnormal distribution (i.e., preceding situation: short length; attack: strongly inappropriate and strongly appropriate relative quality; and, defence: strongly inappropriate, inappropriate and acceptable). The magnitude of changes for parametric data was calculated using the effect size from Cohen's d. The inferences were interpreted based on the following thresholds (Batterham \& Hopkins, 2006): 0.0 - 0.2, trivial; 0.2 - o.6, small; 0.6 - 1.2, moderate; 1.2 - 2.0, large; > 2.0, very large. Additionally, ES for non-parametric data were calculated for pairwise comparisons $(\mathrm{d}=\mathrm{z} / \sqrt{ } \mathrm{n})$ and classified as negligible $(<0.1)$, small (0.1 - 0.29), moderate (0.3 - 0.49), and large (> 0.5) (Frits, Morris, \& Richler, 2012). Several cases of non-normal distribution appeared in match status data (winning vs. drawing vs. losing), which resulted in comparisons by the Friedman test considering the matches as unit of analysis. In addition, Benjamini-Hochberg test with q value set at 0.05 was applied to control the false discovery rate during multiple comparisons within team level, match outcome and match status (Benjamini \& Hochberg, 1995). 


\section{Results}

Scal-Go proposal obtained high agreement levels for inter- (.752 to .919) and intraobservers (.846 to .974) (Altman, 1991). It confirmed high level of observational, operational, and temporal consistency. Two experts from regional and national goalball coaching (three and eighteen years of expertise, respectively) and refereeing contributed and certified the content validity of Scal-Go.

Twenty-four goalball matches resulted in 4527 events including the sequence of preceding situation, attack, and defence team's interactions. On average (mean \pm SD), we obtained $189 \pm 7$ events per match (93 \pm 4 in the first half; $95 \pm 5$ in the second half); $12 \pm 4$ goals per match ( $5 \pm 3$ in the first half; $7 \pm 3$ in the second half). During the matches, most of the preceding situation was based on a balanced self-organized cycle (standard length). However, rounding 7\% of extended length of preceding situation resulted in goals, which demonstrated significant distributions effects compared to standard (rounding 5\%) and short length (rounding $3 \%$ ) preceding situations $[\mathrm{X} 2(2)=8.241 ; \mathrm{p}=.016]$. The attacks presented higher frequency of throws in the central body segment of the defender (acceptable attack), but only 1.3\% of these resulted in goals. On the other hand, rounding 8\% of throws in the body extremities of defenders (appropriate attack) revealed greater goal scored [appropriate attack, X2 (4) = 1810.1; $\mathrm{p}<$.001]. It is important to note that $100 \%$ of throws between two defenders, or between a defender and the goalpost resulted in a goal. Also, neither team scored a goal against. In relation to defensive actions, ball time control $\leq$ 1 second, opponent outside throw, or opponent penalty (i.e., strongly appropriate defence) demonstrated higher frequency during the matches compared to others defence actions (Table 3).

Table 3. Frequency distribution of Scal-Go indicators during 24 elite goalball matches.

\begin{tabular}{lllll}
\hline Relative Quality & Events & $\%$ & Chi-square & p-value \\
\hline Preceding Situation & & & 4577.08 & $<.001$ \\
$\quad$ Short & 206 & 4.6 & & \\
$\quad$ Standard & 3637 & 80.3 & & \\
$\quad$ Extended & 684 & 15.1 & & \\
Attack & & & 4876.23 & $<.001$ \\
$\quad$ Strongly Inappropriate & 110 & 2.4 & & \\
$\quad$ Inappropriate & 516 & 11.4 & & \\
$\quad$ Acceptable & 2597 & 57.4 & & \\
Appropriate & 1218 & 26.9 & & \\
$\quad$ Strongly Appropriate & 86 & 1.9 & & \\
Defence & & & 5266.95 & $<.001$ \\
$\quad$ Strongly Inappropriate & 220 & 4.9 & & \\
$\quad$ Inappropriate & 100 & 2.2 & & \\
$\quad$ Acceptable & 206 & 4.6 & & \\
Appropriate & 1383 & 30.6 & & \\
$\quad$ Strongly Appropriate & 2618 & 57.8 & & \\
\hline
\end{tabular}

Figure 2 shows the effects of team level on Scal-Go indicators. Strong teams demonstrated higher frequency of ball over during defences compared to weak teams (i.e., inappropriate defence, $\mathrm{p}=.003 ; \mathrm{d}=0.35$, small) only. In other test results there were no statistically significant differences. 


\section{Strong teams $\square$ Weak teams}

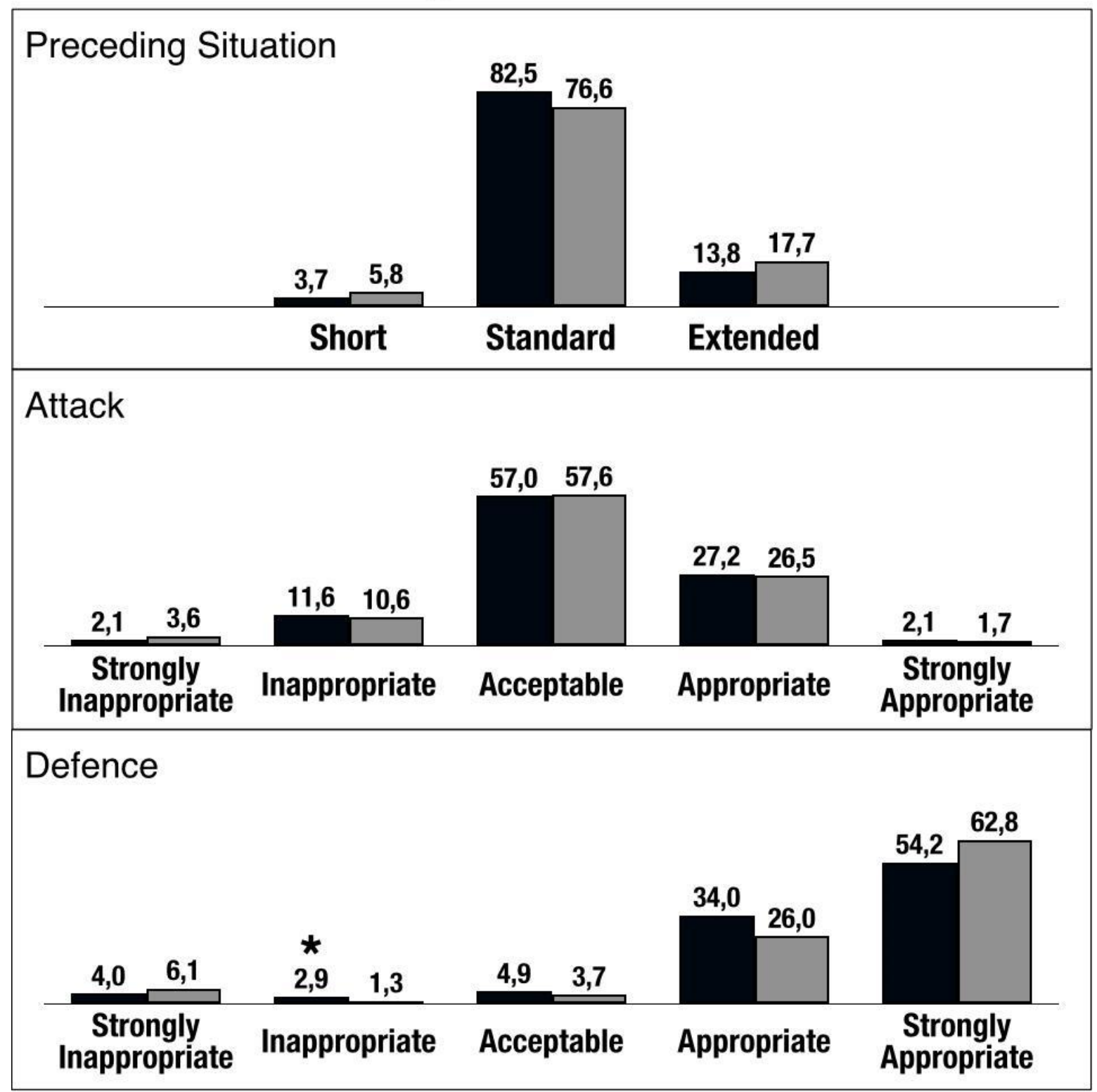

Figure 2. Mean percentage of relative quality in team level comparison between strong vs. weak teams. Note: ${ }^{*} \mathrm{p}<.05$.

Match outcome analysis (Figure 3) showed that winner teams, compared to loser teams, presented high percentage of balanced self-organized cycle (standard length, $\mathrm{p}<. .001 ; \mathrm{d}=$ 1.73, large), with offensive performance based on actions that resulted in a goal (strongly appropriate attack, $\mathrm{p}<.001 ; \mathrm{d}=0.76$, large), defences with ball over (inappropriate defence, $\mathrm{p}=.004 ; \mathrm{d}=0.59$, large), and between 2 to 3 seconds of ball time control (appropriate defence, $\mathrm{p}=.020 ; \mathrm{d}=0.60$, moderate). In addition, loser teams demonstrated higher in counter-attack (short length, $\mathrm{p}=.024 ; \mathrm{d}=0.46$, moderate) and further official interruptions, time-interval, goal, or penalty situations (extended length, $\mathrm{p}<.001 ; \mathrm{d}=1.61$, large) than winner teams. Also, loser teams performed highest frequency of penalties (strongly inappropriate attack, $\mathrm{p}=.008 ; \mathrm{d}=0.54$, large), and conceded major number of goals (strongly inappropriate defence, $\mathrm{p}<.001 ; \mathrm{d}=0.87$, large) compared to winner teams. Additional chi-square analysis showed that $70 \%$ of the first goals in our match sample were performed by teams that won the match $[\mathrm{X} 2(1)=4.17 ; \mathrm{p}<.001]$. 


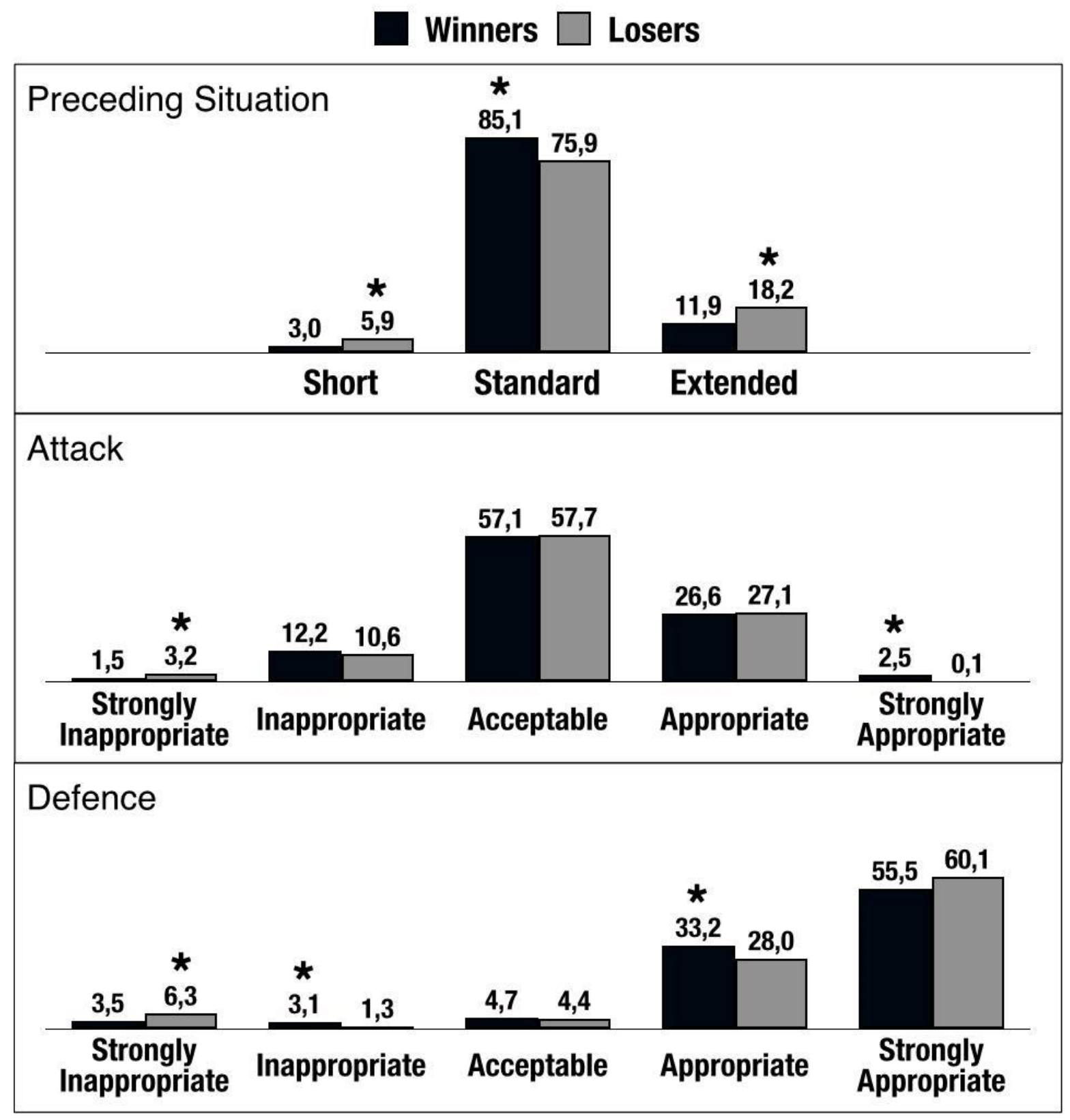

Figure 3. Mean percentage of relative quality in match outcome comparison between winners vs. losers teams. Note: * $\mathrm{p}<.05$.

We observed that winning status presented higher percentage of balanced selforganized cycle (standard length) compared to drawing $(\mathrm{p}<.001)$ and losing status $(\mathrm{p}=$ .oo3; Figure 4). Offensive and defensive phases under winning condition did not result in differences compared to losing status. Nevertheless, losing moments showed higher percentage of preceding situation based to counter-attack strategies (short length) and to extend the attack period (extended length) vs. winning $(\mathrm{p}<.001)$ and drawing situations ( $p$ $<$.o01). Also, losing status presented higher percentage of strongly inappropriate $(\mathrm{p}<$.oo1), acceptable $(\mathrm{p}<.002)$, and appropriate $(\mathrm{p}<.012)$ strategies in offensive principles compared to drawing situations. 


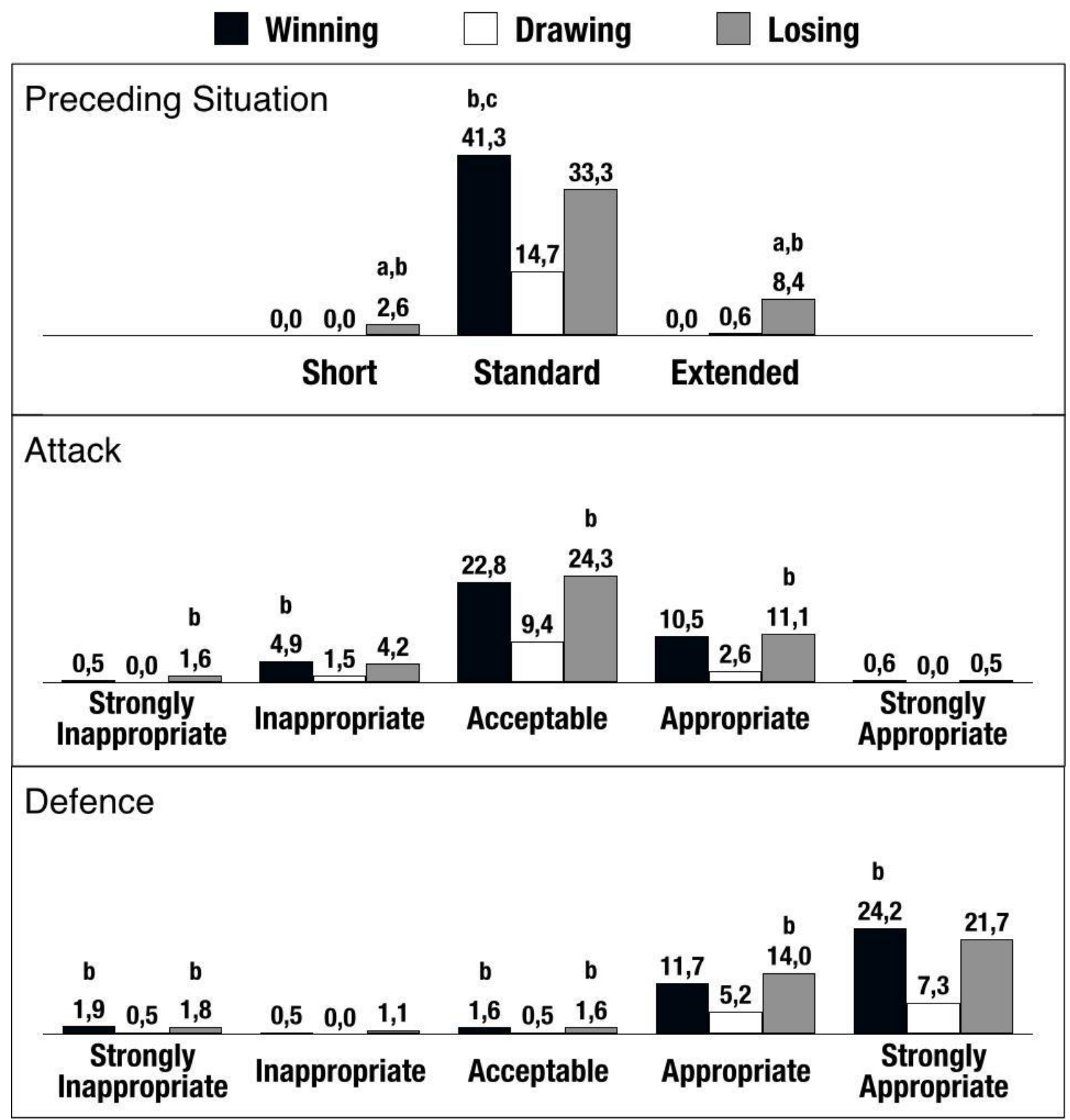

Figure 4. Median percentage of relative quality in match status comparisons. Note: Match status statistics were conducted considering the matches as unit of analysis. In this case, both teams alternated among winning, drawing and losing during the same match (i.e., differently from strong vs. weak teams and winner vs. loser teams). Significant differences: $a=p<.05$ vs. winning; $b=p<$ .05 vs. drawing; $\mathrm{c}=\mathrm{p}<.05$ vs. losing.

\section{Discussion}

The proposal of the Scal-Go system showed relevant situations linked with success and failure in goalball matches. We verified a significant influence of contextual variables on actions performance, which remains constantly altering itself in an attempt to become strongly appropriate during the match and the competition. Based on our analysis, the defensive performance proved to fulfil major strongly appropriate qualifications among goalball teams compared to offensive performance. In this way, we verified specific situations clearly distinct between strong and weak teams, winner and loser teams, and among winning, drawing and losing moments: (i) match interruptions during preceding situations; (ii) accurate shots, finding the gaps between defenders or in their body extremities; (iii) goal scored first; (iv) quick defences with short ball time control; (v) if necessary, defensive infractions; and, (vi) not committing penalties. 
The time-dependent characteristic of goalball provides significant changes in the offensive and defensive phases. After a first defensive ball contact, teams have ten seconds to ensure the ball crosses the court centre line or side line (International Blind Sports Federation, 2020); otherwise, there will be a penalty (Silva et al., 2010). More appropriate actions performance in the defensive phase promotes a complete preceding situation to develop the offensive principles (i.e., the players will have a proper time to plan the actions). Consequently, decision-making queries to prepare attack (who will throw the ball? in which court sector? under which offensive strategy? and for how long attack length?) (Morato et al., 2017) could be self-managed, leading to a strongly appropriate attack during the competition, or even in manipulating settings in training sessions.

If the length of preceding situation is short, the thrower can quickly surprise the opponent defence by using counter-attack strategy (Morato et al., 2012). However, such as aforementioned, $\sim 7 \%$ of extended length of preceding situation resulted in goals, which demonstrated significant distributions effects compared to standard $(\sim 5 \%)$ and short length $(\sim 3 \%)$ preceding situations. Due to match's interruptions, the offensive team can have more time to choose who will throw the ball, to organize the offensive strategy, and to plan the attack length during a period even longer. Throw origin could be switched from the last adversary's hearing ball reference, contributing to reduce the time to react and to promote a low efficient defence by players (Silva et al., 2010). Since official interruptions are inherent in the match, to stimulate interruption's practice and thinking during training process could afford players and teams to handle these situations in a structured context subsidized by coach guidance.

In this study, loser teams and losing status presented higher frequency of short and extended length at preceding situations in attempts to impose different strategies to perform goals. These strategies are related to control the match situation speeding up (i.e., attempts to counter-attack) or promoting an official break during preceding situations (i.e., team time out or substitution). In contrast, winning status enables a control of the match's score that provides their standard-length maintenance. Therefore, the teams did not need to speed up or to interrupt the goalball cycle. In balanced self-organized cycles of attack-defence, teams placed in winning moments perform strongly appropriate attacks finding the gap between defenders or between defender and the goalpost (Link \& Weber, 2018). Considering the need to understand how to find these gaps, origin and target court's sectors (Morato et al., 2017) together with specific instructional and motivational self-talk (Stamou et al., 2007) can provide deeper understanding about attack strategies to generate better conditions to be well-succeed.

The defensive phase is determinant to achieve success (Tosim et al., 2008). Even though the defensive performance accomplished most of strongly appropriate qualifications compared to offensive performance regardless contextual variables, winner teams presented even greater appropriate defences compared to loser teams, as seem in our study. Three defenders in a rational occupation on the court into different tactical systems (e.g., basic triangle, forward triangle, backward triangle, inverse triangle, stair, or barrier) (Morato et al., 2017) may perform the defensive balance and ball reading collectively to increase the defensive efficiency and efficacy (Morato et al., 2012). In this context, outside opponent's throw is almost perfect from who is defending. Considering the high-intensity intermittent characteristics of goalball actions (Alves et al., 2018), without energy expenditure to defend the ball during an occasional opponent's outside shot, the players may settle down with full time length at the preceding situation, which contributes for the subsequent offensive phase.

The player-decision on the attack strategies depends, in part, of the defence qualities. Also, it is important to note that the main aim of the defensive phase is to defend the ball 
(Morato et al., 2012) and it is related to match outcome (Tosim et al., 2008). We verified that winner/strong teams and winning status (compared to drawing status) performed more balls over, the type of infraction that changes de ball possession. When necessary, players preferred to compromise their next offensive action instead of leading to a failure in their defensive phase. A quick block out or even ball over (i.e., defensive infraction) are examples of match strategies during the defensive phase moments. In this way, games for auditory stimulation and defensive balance toward origins of the opponent's throw should be included in practice settings to train players anticipate their defences. Once achieved, it will contribute for lower reaction time (Silva et al., 2010), and possibly, a strongly appropriate defence.

We verified that weak/loser teams and losing status (compared to drawing status) performed greater number of penalty infraction than their counterparts. In fact, penalty shots represent $25 \%$ of the total goals scored in a match (Furtado et al., in press) and can increase in $\sim 50 \%$ the probability of scoring a goal compared to open play/regular match's situations (Magalhães et al., 2015). Due to the body's length of a player in defensive position with arms extended, legs and feet stretched as much as possible can exceed $240 \mathrm{~cm}$, during penalty situation, the defensive area to be covered is almost three times larger than in regular time (Molik et al., 2015). Besides that, the possibilities to hear the ball during defensive balance and to perform throw reading are reduced, since these are conditions that arise from preceding situation in open play (e.g., opponent's attack preparation). Finally, due the increase of rate of success to over $80 \%$ in specific target sectors on the court during penalty situations, these moments must be regarded by coaches (Furtado et al., 2021).

This study has some limitations and insights. During the offensive phase, the target was the only variable considered to qualify actions performance as acceptable, appropriate, and strongly appropriate. Throw origin, ball type, ball time and ball speed should be included in Scal-Go, contributing for full offensive qualification and their potential of uses. In the defensive phase, rebound periods were computed from the first defensive contact of a primary defender until the establishment of ball control. It did not count a second or third defender who also contributed to that specific defence. The tactical system of defence and players' interactions could be a strong constituent element to actions performance scoring. Finally, our sample was composed by male goalball matches from the Paralympic Games Rio 2016, under international rules until that date. The transpose data process must consider the previous and current rules standards for further interpretation (e.g., pass out infraction were excluded in actual guidelines). Further studies must consider other possibilities to classify the team's level during competitions (e.g., margin of victory and percentage of wins).

\section{Conclusion}

The Scal-Go proved to be a robust empirical protocol for goalball match analysis. For comprehending all the possible actions provided during the game and, the information about contextual variables, it highlights the high level of performance analysis. Using the Scal-Go we obtained an authentic match's understanding about this Paralympic Sport. Goalball match arises from attack- defence motions patterns and their interactions with the opponent and the environment. The cycles of these events are influenced by their own actions performance and contextual variables.

Some situations and strategies should be regarded for goalball training: (i) match interruption plays an important situation during the match. For this reason, the offensive teams should take advantage from these situations while defensive teams must interpret this moment with precaution and anticipation; (ii) targets training must be constantly included in goalball practice schedule, considering to find the gap between defenders or to throw close 
this target (i.e., body extremities) lead to a well-succeed attack; (iii) when necessary, defensive infractions could be performed to ensure a safe defence. However, quick defences with short ball time control should be emphasized, since both next actions (i.e., defence and attack) will benefit from this situation; (iv) goal scored first seems to reveal a successful team for that specific match. Coaches should regard these situations to stimulate their athletes or even to prepare them for this disadvantage, and; (v) elite goalball athletes have strongly appropriate defence actions performance; however, penalty situation disrupt this high defence performance and may result in loser and weak teams at the competition.

\section{Perspectives}

Considering the phenomenon discussed in our study, the reflexion of the method and the future possibilities and practical applications that emerged from the results, the development of this article contributed substantially to the field of adapted physical activity. The novel observational system proposed, applied, and validated here proved to be purposeful for goalball's match context. The work was done to improve and to propose a further perspective of analysis in goalball that was not applied before in studies as Morato et al. (2012, 2017 and 2018), Bowerman et al. (2011), Monezi et al. (2019), Link \& Weber (2018) and others. In fact, our hypothesis was confirmed when significant influence from contextual variables in actions performance was observed. In this sense, specific success and failure situations were discovered. Our perspectives are in line with coaches' needs and research gap about actions qualification and contextual influence in goalball's performance. We hope that readers take advantage of this study.

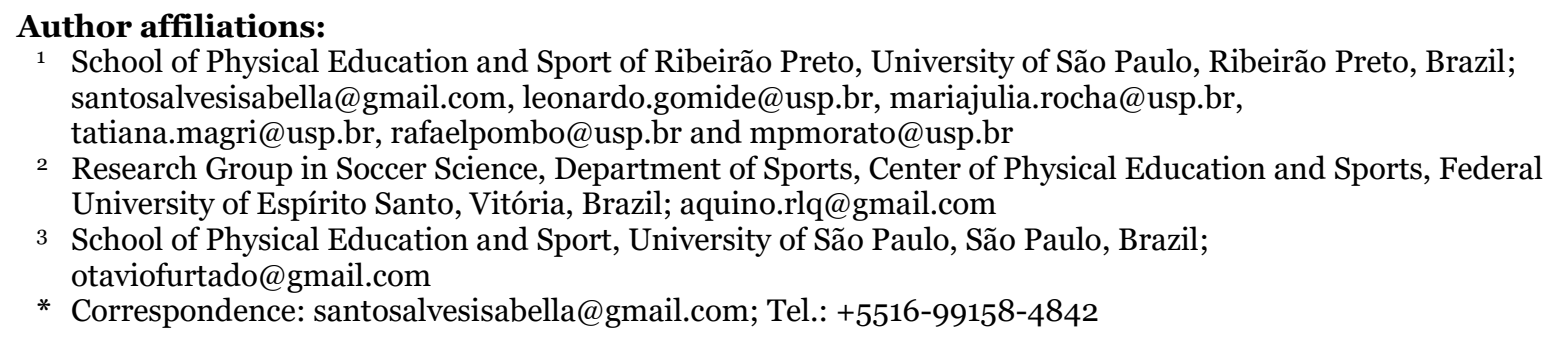

Author Contributions: Conceptualization, I.A. and M.M.; Methodology, I.A, L.G., M.J.R and T.V.; Validation, I.A, L.G. and M.J.R; Formal Analysis, I.A, L.G. and M.J.R; Investigation, I.A, and M.M.; Writing-Original Draft Preparation, I.A; Writing-Review \& Editing, I.A, R.A., R.M. and O.F.; Supervision, M.M.

Funding: This study was financed in part by the Coordenação de Aperfeiçoamento de Pessoal de Nível Superior - Brasil (CAPES) - Finance Code oo1.

Acknowledgments: Sincere thanks to members of Laboratory of Sport Pedagogy, Paralympic Sport and Match Analysis (LAPEEPAJ).

Conflicts of Interest: The authors declare no conflict of interest.

\section{References}

Almeida, C. H., Ferreira, A. P., \& Volossovitch, A. (2014). Effects of match location, match status and quality of opposition on regaining possession in UEFA Champions League. Journal of Human Kinetics, 41(1), 203-214. https://doi.org/10.2478/hukin-20140048

Altman, D.G. (1991). Practical statistics for medical research. Chapman \& Hall.

Alves, I. dos S., Kalva-Filho, C. A., Aquino, R., Travitzki, L., Tosim, A., Papoti, M., \& Morato, M. P. (2018). Relationships between aerobic and anaerobic parameters with gametechnical performance in elite goalball athletes. Frontiers in Physiology, 9(1636), 1-10. https://doi.org/10.3389/fphys.2018.01636

Amorim, M., Corredeira, R., Sampaio, E., Bastos, T., \& Botelho, M. (2010). Goalball: uma modalidade desportiva de competição [Goalball: a competitive sport]. Revista Portuguesa de Ciências do Desporto, 10(1), 221-229. 
Anguera, M. T., \& Mendo, A. H. (2013). La metodología observacional en el ámbito del deporte [Observational methodology in the field of sport]. Revista de Ciencias del Deporte, 9(3), 135-160.

Aquino, R., Carling, C., Palucci Vieira, L. H., Martins, G., Jabor, G., Machado, J., Santiago, P., Garganta, J., \& Puggina, E. (2020). Influence of situational variables, team formation, and playing position on match running performance and social network analysis in brazilian professional soccer players. Journal of Strength and Conditioning Research, 34(3), 808-817. https://doi.org/10.1519/JSC.0000000000002725

Batterham, A. M., \& Hopkins, W. G. (2006). Making meaningful inferences about magnitudes. International Journal of Sports Physiology and Performance, 1(1), 5057. https://doi.org/10.1123/ijspp.1.1.50

Benjamini, Y., \& Hochberg, Y. (1995). Controlling the false discovery rate: A practical and powerful approach to multiple testing. Journal of the Royal Statistical Society: Series B (Methodological), 57(1), 289-300.

Bowerman, S., Davis, R., Ford, S., \& Nichols, D. (2011). Phases of movement of goalball throw related to ball velocity. Insight: Research and Practice in Visual Impairment and Blindness, 4(4), 153-159.

Castellano, J., Casamichana, D., \& Lago, C. (2012). The use of match statistics that discriminate between successful and unsuccessful soccer teams. Journal of Human Kinetics, 31(1), 139-147. https://doi.org/10.2478/v10078-012-0015-7

Costa, I. T., Garganta, J., Greco, P. J., Mesquita, I., \& Maia, J. (2011). Sistema de avaliação táctica no Futebol (FUT-SAT): Desenvolvimento e validação preliminar [System of tactical assessment in Soccer (FUT-SAT): Development and preliminary validation]. Motricidade, 7(1), 69-84. https://doi.org/10.6063/motricidade.7(1).121

Colak, T., Bamaç, B., Aydin, M., Meriç, B., \& Özbek, A. (2004). Physical fitness levels of blind and visually impaired goalball team players. Isokinetics and Exercise Science, 12(4), 247-252. https://doi.org/10.3233/IES-2004-0182

Cronbach, L. J. (1988). Five perspectives on validity argument. In: Wainer, H.; Braun, H. I. (Eds.), Test Validity (pp. 3-17). Lawrence Erlbaum Associates.

Davids, K. (1988). Ecological validity in understanding sport performance: some problems of definition. Quest, $40(2), 126-136$. https://doi.org/10.1080/00336297.1988.10483894

Fleiss, J. L., Levin, B., \& Paik, M. C. (2013). Statistical methods for rates and proportions. New Jersey: John Wiley \& Sons.

Francis, J., Oen, A., \& Peters, D. M. (2019a). A new reliable performance analysis template for quantifying action variables in elite men's wheelchair basketball. Frontiers in Psychology, 10 ,16. https://doi.org/10.3389/fpsyg.2019.00016

Francis, J., Owen, A., \& Peters, D. M. (2019b). Making every "point" count: Identifying the key determinants of team success in elite men's wheelchair basketball. Frontiers in Psychology, 10, 1431. https://doi.org/10.3389/fpsyg.2019.01431

Francis, J. W., Owen, A. J., \& Peters, D. M. (2021). Predicting field-goal success according to offensive, defensive and contextual variables in elite men's wheelchair basketball. PLoS ONE, 16(1), e0244257. https://doi.org/10.1371/journal.pone.0244257

Fritz, C. O., Morris, P. E., \& Richler, J. J. (2012). Effect size estimates: current use, calculations, and interpretation. Journal of Experimental Psychology: General, 141(1), 2-18. https://doi.org/10.1037/a0024338

Furtado, O. L. P., Häyrinen, M., Alves, I. S., Travitzki, L., \& Morato, M. P. (2021). Factors associated with penalty outcome on male elite goalball. Adapted Physical Activity Quarterly, 38(3), 506-518. https://doi.org/10.1123/apaq.2020-0117

Gómez, M. Á., Pérez, J., Molik, B., Szyman, R. J., \& Sampaio, J. (2014). Performance analysis of elite men's and women's wheelchair basketball teams. Journal of Sports Sciences, 32(11), 1066-1075. https://doi.org/10.1080/02640414.2013.879334

Hopkins, W. G. (2000). Measures of reliability in sports medicine and science. Sports Medicine, 30(1), 1-15. https://doi.org/10.2165/00007256-200030010-00001

Hughes, M. D., \& Bartlett, R. M. (2002). The use of performance indicators in performance analysis. Journal of Sports Sciences, 20(10), 739-754.

https://doi.org/10.1080/026404102320675602 
International Blind Sports Federation. (2020, May 6). Classification Rules. Sport Classes Profiles for Athletes with Vision Impairment.

https://www.ibsasport.org/sports/files/1180-Rules-2018-2021-IBSA-Goalball-Rulesand-Regulations-(Effective:--6-May-2020).pdf

Lago, C. (2009). The influence of match location, quality of opposition, and match status on possession strategies in professional association football. Journal of Sports Sciences, 27(13), 1463-1469. https://doi.org/10.1080/02640410903131681

Link, D., \& Weber, C. (2018). Finding the gap: An empirical study of the most effective shots in elite goalball. PLoS One, 13(4). https://doi.org/10.1371/journal.pone.0196679

Magalhães, T. P., Furtado, O. L. P. C., Morato, M. P., Gamero, D. H., \& Misuta, M. S. (2014, November 05-07) Análise cinemática das ações ofensivas no goalball em situação de jogo: deslocamento do jogador e arremesso [Kinematic analysis of offensive actions in goalball in game situation: player displacement and pitch] [Poster presentation]. IV Congresso Paradesportivo Internacional, Florianólis, SC, Brazil.

Marszałek, J., Gómez, M. Á., \& Molik, B. (2018). Game performance differences between winning and losing sitting volleyball teams regarding teams' ability. International Journal of Performance Analysis in Sport, 18(2), 367-379.

https://doi.org/10.1080/24748668.2018.1477027

McGarry, T., Anderson, D. I., Wallace, S. A., Hughes, M. D., \& Franks, I. M. (2002). Sport competition as a dynamical self-organizing system. Journal of Sports Sciences, 2O(10), 771-781. https://doi.org/10.1080/026404102320675620

Molik, B., Morgulec-Adamowicz, N., Kosmol, A., Perkowski, K., Bednarczuk, G., Skowronski, W., Gomez, M. G., Koc, K., Rutkowska, I., \& Szyman, R. J. (2015). Game performance evaluation in male goalball players. Journal of Human Kinetics, 48(1), 43-51. https://doi.org/10.1515/hukin-2015-0090

Molik, B., Morgulec-Adamowicz, N., Marszałek, J., Kosmol, A., Rutkowska, I., Jakubicka, A., ... Gómez, M. Á. (2017). Evaluation of game performance in elite male sitting volleyball players. Adapted Physical Activity Quarterly, 34(2), 104-124. https://doi.org/10.1123/apaq.2015-0028

Monezi, L. A. A., Magalhães, T. P. P., Morato, M. P. P., Mercadante, L. A. A., Furtado, O. L. P. C., \& Misuta, M. S. S. (2019). Time-motion analysis of goalball players in attacks: differences of the player positions and the throwing techniques. Sports Biomechanics, 18(5) 470-481. https://doi.org/10.1080/14763141.2018.1433871

Morato, M. P., Furtado, O. L. P., Gamero, D. H., Magalhães, T. P., \& de Almeida, J. J. G. (2017). Development and evaluation of an observational system for goalball match analysis. Revista Brasileira de Ciências do Esporte, 39(4), 398-407.

https://doi.org/10.1016/j.rbce.2016.08.002

Morato, M. P., Gomes, M. S. P., \& Almeida, J. J. G. de. (2012). Os processos autoorganizacionais do goalball [The self-organizations processes of goalball]. Revista Brasileira de Ciências do Esporte, 34(3), 741-760. https://doi.org/10.1590/So10132892012000300015

Morato, M.P., Menezes, R. P., Fonseca, S., \& Furtado, O. L. P. D. C. (2018). Faster balls increase the probability of scoring a goal in female and male elite goalball. Revista Brasileira de Ciencias do Esporte, 4O(4), 427-434. https://doi.org/10.1016/j.rbce.2018.03.027

O'Donoghue, P. O. (2010). Research methods for sports. Routledge.

Picolo, J. G. D., Travitzki, L., Alves, I. dos S., \& Morato, M. P. (2021). Estratégias ofensivas e defensivas eficazes no goalball [Effective offensives and defensives strategies in Goalball] Motrivivência, 33(64), 1-19. https://doi.org/10.5007/2175-

8042.2021.e82157

Silva, G. P., Pereira, V. R., Deprá, P. P., \& Gorla, J. I. (2010). Tempo de reação e a eficiência do jogador de goalball na interceptação/defesa do lançamento/ataque [Reaction time and efficiency of the goalball player in interception/defense of throwing/attack]. Motricidade, 6(4), 13-22.

Silva, P., Garganta, J., Araújo, D., Davids, K., \& Aguiar, P. (2013). Shared knowledge or shared affordances? Insights from an ecological dynamics approach to team 
coordination in sports. Sports Medicine, 43(9), 765-772.

http://doi.org/10.1007/s40279-013-0070-9

Stamou, E., Theodorakis, Y., Kokaridas, D., Perkos, S., \& Kessanopoulou, M. (2007). The effect of self-talk on the penalty execution in goalball. The British Journal of Visual Impairment, 25(3), 233-247. https://doi.org/10.1177/0264619607079800

Taylor, J. B., Mellalieu, S. D., James, N., \& Shearer, D. A. (2008). The influence of match location, quality of opposition, and match status on technical performance in professional association football. Journal of Sports Sciences, 26(9), 885-895. https://doi.org/10.1080/02640410701836887

Taylor, J., Mellalieu, S., James, N., \& Barter, P. (2010). Situation variable effects and tactical performance in professional association football. International Journal of Performance Analysis in Sport, 10, 255-269. https://doi.org/10.1080/24748668.2010.11868520

Thomas, J. R., Nelson, J. K., \& Silverman, S. J. (2009). Métodos de pesquisa em atividade física [Research methods in physical activity]. Artmed Editora.

Tosim, A., Junior, A. P., Leitão, M. T. K., \& Simões, R. (2008). Sistemas técnicos e táticos no goalball. Revista Mackenzie de Educação Física e Esporte, 7(2), 141-148.

(C) 2022 by the authors. Submitted for possible open access publication under the terms and conditions of the Creative Commons Attribution (CC BY) license (http://creativecommons.org/licenses/by/4.0/). 